\title{
BIOMEDICAL ENGINEERING SUPPORT
}

Contract AT(11-1)-2155-14

Principal Investigator:

W. J. Kolff, M.D., Ph.D.

Co-Investigator and Prepared by:

L. M. Smith, M.S.

G. M. Sandquist, Ph.D.
NOTICE

This report was prepared as an account of work sponsored by the United States Government. Neither the United States nor the United States Energy Research and Development Administration, nor any of their employees, nor any of their contractors, subcontractors, or their employees, makes any warranty, express or implied, or assumes any legal liability or responsibility for the accuracy, completeness or usefulness of any information, apparatus, product or process disclosed, or represents that its use would not infringe privately owned rights.

First Quarterly Report

for

August 16 to November 15, 1974

Institute for Biomedical Engineering and

Division of Artificial Organs

Building 518

University of Utah

Salt Lake City, Utah 84112 


\section{DISCLAIMER}

This report was prepared as an account of work sponsored by an agency of the United States Government. Neither the United States Government nor any agency Thereof, nor any of their employees, makes any warranty, express or implied, or assumes any legal liability or responsibility for the accuracy, completeness, or usefulness of any information, apparatus, product, or process disclosed, or represents that its use would not infringe privately owned rights. Reference herein to any specific commercial product, process, or service by trade name, trademark, manufacturer, or otherwise does not necessarily constitute or imply its endorsement, recommendation, or favoring by the United States Government or any agency thereof. The views and opinions of authors expressed herein do not necessarily state or reflect those of the United States Government or any agency thereof. 


\section{DISCLAIMER}

Portions of this document may be illegible in electronic image products. Images are produced from the best available original document. 
SUMMARY:

During the quarter covered by this progress report (August 16, 1974, to November 15, 1974), two implantation experiments were conducted to further develop surgical procedures as well as to assess the overall performance and adequacy of the , AEC Blood Pump and ventricles. Both experiments were directed primarily at determining and improving pump and ventricular efficiency, improving surgical procedures and evaluating the reliability of the blood pump components, which include the flexible drive shaft, the blood pump drive mechanism and the blood handling components .

Experiment No. 14 (AEC) was scheduled as a long term experiment in a $110 \mathrm{~kg}$ female holstein calf. The electric motor was implanted in the abdomen which powered AEC Blood Pump No. 2 via a $1 / 8$ "flexible drive shaft. Surgical implantation required 3.5 hours. Seven hours after surgery aortic pressure was $120 / 76 \mathrm{~mm} \mathrm{Hg}$ with a mean filling pressure of $5 \mathrm{~mm} \mathrm{Hg}$. Motor torque was $10 \mathrm{oz}$. - in. and motor temperature $37.5^{\circ} \mathrm{C}$. The animal attempted to stand at this time. Excessive bleeding from the thorax (over $2600 \mathrm{cc}$ ) dictated reopening the chest at 12 hours into the experiment to correct the blood loss. Sporadic high torques were observed for the implanted electric motor, and blood pump performance was somewhat influenced by animal position. At 32 hours high motor torques resulted in a four minute loss of power to the blood pump while the motor controller was refused. Torque values of $13.5 \mathrm{oz}$. - in. and greater were measured on the motor controller. Motor speed was reduced to $700 \mathrm{rpm}$ to prevent further power interruption. At 87 hours the animal 
exhibited very weak reflexes and was terminated.

Experiment No. 15 (AEC) was a scheduled long-term total heart replacement experiment in a $98 \mathrm{~kg}$ male holstein calf. A water cooled electric motor implanted in the abdomen provided power to the blood pump via a $3 / 16^{\prime \prime}$ drive shaft core contained in a reinforced casing. During surgical implantation of the AEC Blood Pump air entrained blood appeared in the right ventricle during heart-lung bypass. The thorax was flooded with saline and rapid closure was made to eliminate further air leakage into the blood. The animal stood six hours after surgery but continuing blood drainage from the chest drain tubes necessitated reopening of the thorax to correct bleeding. Later a blood transfusion improved blood pressures and the calf exhibited good reflexes. Average power delivered to the blood ranged from 3.9 to 4.2 watts at a peak aortic pressure of $105 \mathrm{~mm} \mathrm{Hg}$. About 70 hours postoperative respiratory function began to deteriorate and $100 \%$ oxygen repiration failed to maintain adequate blood gases. The calf was terminated after 100 hours.

Autopsy revealed that the calf had pneumonia with adhesions which was responsible for the pulmonary insufficiency encountered. However, throughout the experiment pump requirements never exceeded 5.1 watts and averaged about 3.9 watts. The pump maintained sufficient cardiac output and the flexible drive shaft performed well throughout the experiment. Later observation showed no signs of significant deterioration or kinking of the shaft.

Facilities, supplics and procedures are in preparation for receiving and utilizing the thermal converter and plutonium-238 power source when they are available for the Institute for Biomedical Engineering. A safe and secure plutonium storage facility is now ready and personnel are being instructed in operational procedures related to the plutonium and thermal converter. 
Mr. Lee Smith has devoted $80 \%$ of his time to this project during the reporting period. Furthermore, Dr. Gary Sandquist has devoted 33\% of his time to the project during the quarter and Dr. Don Olsen has devoted $25 \%$ of his time to the project during the quarter. Contract requirements are thus being filled. 


\section{SUMMARY REPORT ON AEC TOTAL ARTIFICIAL}

\section{HEART REPLACEMENT}

Experiment (TH74 C31 D31 AEC 14): Conducted on August 16, 1974

Experiment No. 14 was planned as a long-term sterile experiment to evaluate the AEC blood pump dxiven by a water cooled electric motor implanted in the abdomen, with a reinforced flexible driveshaft and casing.

Surgical procedure: A sternal split surgical procedure was performed by Drs. Don Olsen, Hartmut Oster, Jack Kolff, and Ken Watanabe. The experimental animal was a holstein calf approximately $110 \mathrm{~kg}$ in weight. AEC Blood Pump No. 2 was used, with Silastic ventricles coated with Dacron fibrils and fitted with BjorkShiley pyrolytic carbon valves. The AEC blood pump mechanism and Silastic ventricles were autoclaved prior to surgery. The implantable electric motor and cooling system, along with the flexible driveshaft coupling mechanism were gas sterilized 72 hours prior to surgery with ethylene oxide. The animal was anesthetized with Brevane followed by fluothane. Parameters monitored during the course of the experiment were aortic pressure, central venous pressure, left arterial pressure, right atrial pressure, and pulmonary arterial pressure. Mechanical parameters measured were motor speed, torque, electric motor temperature and the vacuum maintained on the blood pump mechanism.

The experimental animal had preoperative lung function which indicated normal breathing capacities. Heart-lung bypass time was approximately $133 \mathrm{~min}$. The surgery lasted approximately $3 \frac{1}{2}$ hours.

Postoperative recovery: One hour into the experiment with the animal off the surgical table and into the postoperative cart the average motor torque was 
9 in. - oz. with a motor temperature of $40.5^{\circ} \mathrm{C}$. Arterial blood pressure was adequate at $120 / 190 \mathrm{~mm} \mathrm{Hg}$ and a filling pressure of approximately $4 \mathrm{~mm} \mathrm{Hg}$ on the right and $4 \mathrm{~mm} \mathrm{Hg}$ on the left heart. At 7 hours into the experiment the average motor torque was $10 \mathrm{oz}$. - in., motor temperature was $37.5^{\circ} \mathrm{C}$, aortic pressure was $120 / 76 \mathrm{~mm} \mathrm{Hg}$ with an average filling pressure of $5 \mathrm{~mm} \mathrm{Hg}$ on the left side. At this point the animal attempted to stand and pulled out the power line which was immediately reconnected. At 10 hours into the experiment the animal was repositioned and a high torque on the electric motor was noticed when the animal's right front shoulder was lifted. The average torque was $10.5 \mathrm{oz}$. - in, with high torque values approaching $12-12.5$ oz. - in. of torque. At 10 hours into the experiment $2600 \mathrm{cc}$ had accumulated in the chest dxainage bottle. There seemed to be a tremendous amount of bleeding at this time. Continually the animal attempted to stand. In order to correct bleeding the animal was put back on the surgery table at 12 hours into the experiment and at 14 hours the animal was off the table again. At 16 hours into the experiment, 2 hours after the second surgery, the animal began to show signs of awakening from the anesthesia. The animal's temperature was approximately $36^{\circ} \mathrm{C}$ and again was restless and tried to stand. The electrical connector connecting the electric motor speed controller with the electric motor began to have intermittant connection problems, resulting in tremendous over-speeding of the electric motor. Occasionally the motor would shut off altogether. At 17 hours into the experiment the electric ventricle connector was resoldered and epoxied to eliminate this problem. At 20 hours into the experiment the aortic blood pressure was $120 / 100$ with a filling pressure on the left of $5 \mathrm{~mm} \mathrm{Hg}$ and $6 \mathrm{~mm} \mathrm{Hg}$ on the right side.

Drainage from the chest drainage tubes had apparently diminished with the second surgery, solving the bleeding problem that we had scen earlicr in the 
experiment. At 32 hours into the experiment the fuse on the motor controller burned out because of the high torque condition and power was off for approximately 4 minutes. At this time the motor speed was reduced to approximately 700 RPM to reduce the torque on the motor. High torques on the electric motor were noticed every time the animal changed his position or was moved by the calf sitters. At 45 hours into the experiment the reflexes of the animal were fair, some eyelid movement. Again, slight movement of animal would cause high torque conditions and blood pressure would also increase. The blood pump performance seemed to be somewhat position sensitive. At 58 hours into the experiment the animal was very calm and seemed to be extremely constipated. There was some involuntary type muscle spasm, but the animal was unable to move. At 65 hours into the experiment adequate blood pressures and blood gases were maintained while the animal was on $40 \%$ oxygen with the Bird respirator. The aortic blood pressures were $110 / 75$ with a filling pressure of approximately $3 \mathrm{~mm} \mathrm{Hg}$. with very high torques, $13.5 \mathrm{oz}$. - in. and greater. At 80 hours into the experiment reflexes were very poor although the animal was maintained adequately on $60 \%$ oxygen with the Monoghan respirator. Aortic pressures were $110 / 80 \mathrm{~mm} \mathrm{Hg}$. At 87 hours it appeared as though further postoperative care would no longer support the animal. The animal was terminated and an autopsy performed.

Autopsy report: Upon examining the artificial heart inside the chest cavity the relative position of the heart to the sternum was very good, with very little dead space between the snout of the blood pump and the sternum. There was no kinking of the aorta or pulmonary artery and there was very little compression of the atria or the superior or inferior vena cava. Upon closer examination of the quick connects, they all appeared to be tightly sealed with the exception of the pulmonary artery quick 
connect which appeared to be pulling out of the ventricle.

It was noted that the animal appeared to be dehydrated. The right lung weighed approximately $910 \mathrm{gm}$, the left lung $700 \mathrm{gm}$. This totalled approximately $1600 \mathrm{gm}$ which gave no indication of excessive weight in the lungs. The liver weighed $3100 \mathrm{gm}$ which is greater than the $1.65 \%$ of body weight which is considered, normal.

The kidneys did not appear to be enlarged. There were a few infarcts in the left kidney and numerous small infarcts in the right kidney. Upon examination of the spleen there were some hemorrhages around the secum, sections of the brain were sent for histopathology and their results were as follows: "Microscopic examination of three sections of the brain at various levels revealed some perivascular edema with rather severe edematous changes within the parenchyma of the brain. It does appear to be a focal area of corticomalacia, which may have resulted from being exposed to water during the removal process. There is also evidence of neurinal shrinking throughout the brain tissue. This is generalized and may be associated with anoxia to the brain. There are some layers within the brain which appear to be markedly congested."

In summary: This experiment was successful in that we achieved the longest implant time with a totally implantable electric motor and driveshaft. Difficulties arose with the increased bleeding early in the experiment and having to reopen the animal's chest to solve its bleeding problems which always causes risk to the animal and the possibility of throwing emboli into the organs, especially the brain . However, the second surgical procedure did in fact stop the bleeding and the animal came out of the second operation satisfactorily. We were able to perfuse the animal adequately and keep adequate blood pressures and blood gas values within normal 
limits. We did experience problems with high torques, with the animal in varying positions. This did give us some experience as to what kind of positions the animal could maintain without overloading the flexible drive shaft. In one of these attempts we did blow the fuse to the electrical controlling unit of the electric motor, but this was corrected with an insertion of a new fuse into the motor controller. In the latter. half of the experiment, although bleeding was controlled, there was evidence of a comatose condition due to possible brain damage and the animal was more or less motionless. This was not, perhaps, a fair test of the pumping capacity of the AEC blood pump, but it did in fact allow us to experiment with maneuvering the animal in varying positions to look at the high and low torque values obtained from this position change.

Cooling of the electric motor seemed to function well with the water cooling system maintained on the electric motor. There were no overheating incidences seen. The animal was terminated at 87 hours, since further postoperative care could not prolong the life of the animal adequately. 


\section{SUMMARY REPORT ON AEC TOTAL ARTIFICIAL HEART REPLACEMENT \\ EXPERIMENT (TH74 C41 AEC 15)}

Conducted on November 21, 1974

The purpose for experiment AEC 15 was a long-term sterile experiment conducted to evaluate the AEC blood pump driven by a water cooled electric motor implanted in the abdomen with a $3 / 16 "$ drive shaft core and reinforced drive shaft casing. Surgeons involved in the total heart experiment were Drs. Don Olsen, Jack Kolff, Felix Unger, and Mr. Lee Smith.

A $98 \mathrm{~kg}$ male holstein calf was used. The ventricles were fibrilized Silastic rubber and mounted on WANL Blood Pump No. 2 with polycarbonate quick connects. The driving system was an abdominally implanted, water cooled electric motor. Anesthesia was Brevane induction followed by fluothane. Mechanical and physiological parameters measured included aortic pressure and central venous pressure, with both of these lines removed after 24 hours. Thereafter, continuous monitoring of aortic pressure, right atrial pressure, left atrial pressure and pulmonary arterial pressure was made. Mechanical parameters monitored included RPM of the electric motor, motor torque, vacuum on the AEC Blood Pump and electric motor temperature.

Preoperative pulmonary function tests were made on this calf and the functional residual capacity was measured at $5,440 \mathrm{cc}$. This value was within normal limits for a calf of this wcight.

Surgery lasted for approximately $3 \frac{1}{2}$ hours with the animal on heart-lung bypass for 140 minutes. The polycarbonate quick connects worked very well. There was no leaking around the quick connect seal. Difficulty did arise where the quick connects are fastened to the ventricle snouts themselves. This problem was corrected, however, during surgery. During surgery, as preparations were made 
to go off the heart-lung bypass, some foam appeared in the right ventricle and there appeared to be a source of air leaking into the blood stream. At this time it was decided to flood the chest with saline to prevent additional air leaking into the blood. This necessitated an emergency closure procedure that did not allow the surgeons to isolate and stop several small sources of bleeding near the sternum incision.

Postoperative Results: At 6 hours into the experiment the animal was able to stand with some assistance from the calf sitters. The animal stood for $4-5$ minutes. At this time there was a large amount of bleeding from the chest drainage tubes (approximately 2,000 cc had been collected). At 9 hours into the experiment the bleeding had not stopped so it was decided to reopen the animal on the operating table in order to eliminate the source of bleeding if possible. During this second surgical operation there was no single point located that could be attributed to the excessive bleeding. However, it was found that some bleeding was coming from the sternal split incision. This was remedied as much as possible and the animal was sewed up and the operation was completed at 10 hours into the experiment. During this second operation blood handling components appeared to be functioning satisfactorily and there was no source of bleeding connected with the polycarbonate quick connects. Between 11 and 17 hours into the experiment the animal's aortic blood pressure slowly began to drop as a result of a loss of blood. At 20 hours into the experiment fresh blood was administered with the resulting increase in blood pressure (see Figure 1) and parameters of the animal appeared to be much better. At 19 hours into the experiment the animal's blood pressure was $130 / 90 \mathrm{~mm} \mathrm{Hg}$ with a filling pressure of $0 \mathrm{~mm}$ $\mathrm{Hg}$ in the right atrium and $0 \mathrm{~mm} \mathrm{Hg}$ in the left atrium. The pulmonary arterial pressure had a mean value of $25 \mathrm{~mm} \mathrm{Hg}$. Average power input of the electric motor was approximately 5 watts*. Bleeding from the chest began to reduce and it was ap-

*1. 1 watts of the 5 watts was due to inherent mechanical losses in the electric motor bearings and brushes. Future power level references will not include these inherent losses. 
parent that the second operation had succeeded in stopping the source of bleeding .

Between 20 and 30 hours into the experiment the animal was moving its head, had excellent reflexes, and was on $50 \%$ oxygen with mechanical breathing assistance. Again, it was noted that average power requirements were much lower than we had seen in previous experiments. Average power measurements were running between 3.9 and 4.2 watts from the electric motor. Between 30 and 40 hours into the experiment the animal was maintained with respiratory assistance on $50 \%$ oxygen. Power requirements were still low and we were maintaining adequate circulatory assistance. Average blood pressure measured at the aorta was 100-105 $\mathrm{mm} \mathrm{Hg}$.

Between 40 and 50 hours into the experiment the animal was quiet but its reflexes were still good. At 47 hours into the experiment, dopamine was administered to increase the blood pressure. The blood pressure increased until the mean pressure was between $130-150 \mathrm{~mm} \mathrm{Hg}$ with a correspondingly increased torque. Average power requirements went as high as 4.9 watts for a short period of time until the effects of the dopamine had worn off. Dopamine was administered to test, in effect, the animal's ability to shift its blood pressures in response to a stimulant. Dopamine has the effect of constricting the blood vessels and potentially increasing the blood pressure and the cardiac output. This is apparently why we see a corresponding increase in power requirements. Between 50 and 60 hours postoperative reflexes were still good; the animal was quiet; electric motor temperature was within normal body temperature limits and all physiological parameters appeared to be normal.

Between 60 and 70 hours postoperative the animal's respiratory functions started to deteriorate. The respirator was adjusted to $100 \%$ oxygen and the tidal volume was increased to $2,400 \mathrm{cc}$. Again, power requirements were low with an average of about 3.9 to 4.1 watts of power delivered. Blood pressures ranged from an average 
of $100 \mathrm{~mm} \mathrm{Hg}$ down to a low of $75 \mathrm{~mm} \mathrm{Hg}$. At this point it became apparent that the animal's lungs were deteriorating and we would not be able to take the animal off the respirator. Again, dopamine was administered to test the animal's ability to react to vasoconstrictors. Between 70 and 80 hours the animal's reflexes were still responsive; the animal was, however, quiet and not attempting to stand. The animal. still required mechanical breathing assistance and $100 \%$ oxygen to maintain adequate blood gases. At 80 hours into the experiment the mean blood pressure was $135 \mathrm{~mm}$ $\mathrm{Hg}$ with an average power of 4.2 watts delivered from the electric motor. Between 80 and 90 hours postoperative respiratory assistance became increasingly more difficult to maintain adequate blood gases with the respirator, even though the animal was on $100 \%$ oxygen. Between 90 and 100 hours it became obvious that further postoperative care would not improve the animal's condition. The animal's lung appeared unable to provide sufficient respiratory assistance and at a little after 100 hours the animal was terminated.

Autopsy Report: The holstein calf, at termination, weighed $105 \mathrm{~kg}$. He had had some subcutaneous edema of the legs and a very thick edematous plaque extending on the right side from the electric motor, along the sternum. At termination the calf had a jugular pressure higher than he had earlier but his right atrial pressure had a mean of $8 \mathrm{~mm} \mathrm{Hg}$. Using air driving pressure in the Monaghan of $40 \mathrm{~cm}$ of water, we were only able to get about $1,100 \mathrm{cc}$ tidal volume. At $100 \%$ oxygen the $\mathrm{pCO}_{2}$ was about 60 and the $\mathrm{pO}_{2}$ only 47 . However, the $\mathrm{pH}$ was an acceptable 7.38 (this was blood from the pulmonary artery). Until termination the calf still had good reflexes and would respond to the slightest touch over the skin of the various parts of the body . 
When the calf's chest was opened we found an excellent fit of the AEC blood pump in the calf's chest, the modified right ventricle seemed to alleviate any kinking in the pulmonary artery graft (as had been seen in earlier experiments). This is what we attributed the lower power requirements to during the course of the experiment. In earlier experiments the kinking of the pulmonary artery graft could easily have resulted in increased power requirements to circulate the blood through the system.

At autopsy this calf had pneumonia with adhesions, particularly over the ventral portions of the right apical lobe at the time of surgery. Furthermore, the lungs received a severe insult in the amount of foam that we had in the right ventricle and the pulmonary outflow tract before we submerged the artificial heart into saline and quickly closed the animal's chest. This emergency closure necessitated reopening (as mentioned previously) approximately 10 hours later, looking for the sources of hemorrhage. The hemorrhage was not obvious but it was believed to have occurred from the sternal wires and incision. The chest was cleaned up and evacuated of all blood and blood clots and the animal's chest closed. Prior to the second surgery the animal rose to its feet with assistance and stood for 4-5 minutes. We were unable to wean the animal from the respirator and we had suspected severe pulmonary complications throughout the duration of this experiment. We were able, however, to maintain normal physiological pressures throughout the experiment and normal blood gases were maintained until the last 20 hours. It was rather unusual that we had difficulty maintaining adequate oxygenation of the blood. Terminally, the usual events occurred when we were able to eliminate $\mathrm{CO}_{2}$ and the $\mathrm{pCO}_{2}$ went up to a very high level.

There was $200 \mathrm{cc}$ of pleural effusion in the right thorax, 1,700 cc of ascites fluid that was straw colored. The cardiac lobe of the right lung was kinked and 
totally collapsed intermediate lobe of the right lung. The right lung was very heavy, $1,700 \mathrm{gm}$ and very pneumonic. The left lung weighed $1,100 \mathrm{gm}$.

The left kidney weighed $240 \mathrm{gm}$, the right kidney weighed $260 \mathrm{gm}$. We had a massive pulmonary hemorrhage in the diaphragmatic lobe of the left lung containing an estimated 250-300 cc. The left lung had purulent yellow bronchial secretions. This AEC calf No. 15 was terminated because of its severe lung problems rather than a mechanical failure in the driving system.

No compression of superior or inferior vena cava was noted, no compression of the atria was seen and, as has been mentioned before, there was an excellent fit of the heart into the chest cavity with the heart leaning close to the sternum of the animal. There was a small thrombus buildup initiating at the quick connect in the left atrium, on the posterior wall, about $1 \frac{1}{2} \mathrm{~cm}$ away from the atrial pressure tap. There was a lot of hemorrhaging around the electric motor. Peticheal hemorrhages of the serrosal surface of the cecum. The urinary bladder contained $300 \mathrm{cc}$ of normal appearing urine.

The liver weighed 3,150 gm. We had some thrombus formation in the DH junction near the drive shaft on the posterior aspect of the heart. It appears that maybe the right diaphragm was touching the housing in the greatest curvature.

Summary of AEC No. 15: Although AEC No. 15 was terminated after only 100 hours, it proved to be one of the most informative experiments to date in the AEC program. Several parameters were improved in this experiment which give evidence of much longer survival times to be obtained in the future.

1. The fit of the AEC blood pumps in the chest has been improved with a modification of the right outflow port. That is, the pulmonary arterial graft 
connection to the right ventricle. In earlier experiments this has always been kinked to one degree or another and probably has resulted in increased power demands for pumping adequate amounts of blood. In this experiment there was no kinking of the pulmonary artery graft and we attributed this to the low power demands .

2. Throughout the course of the experiment average power requirements from the electric motor never exceeded 5.1 watts. Average power was only about

\section{7 to 4.1 watts of power.}

3. The electric motor operated well, the cooling system maintained the motor temperature at the normal body temperature of the calf. The flexible drive shaft operated well throughout the course of the experiment and at autopsy showed no serious signs of deterioration or kinking.

4. The AEC blood pump itself and ventricles operated very effectively and managed to pump sufficient blood to maintain adequate blood gases and total body perfusion.

5. The use of the new plastic, polycarbonate quick connects increased the speed with which these connections of these grafts and great vessels were made and appear to work much better than the stainless steel quick connects used in earlier experiments. Although we performed a preoperative pulmonary function analysis and the animal's lungs appeared to be normal, the animal actually did indeed have severe bronchial pneumonia, which with the addition of the two surgeries, deteriorated the lungs to a point that postoperative care could not keep up with the lung's decreasing ability to maintain adequate oxygenation. Had this animal not had preoperative lung problems, survival times would have been considerably longer. 


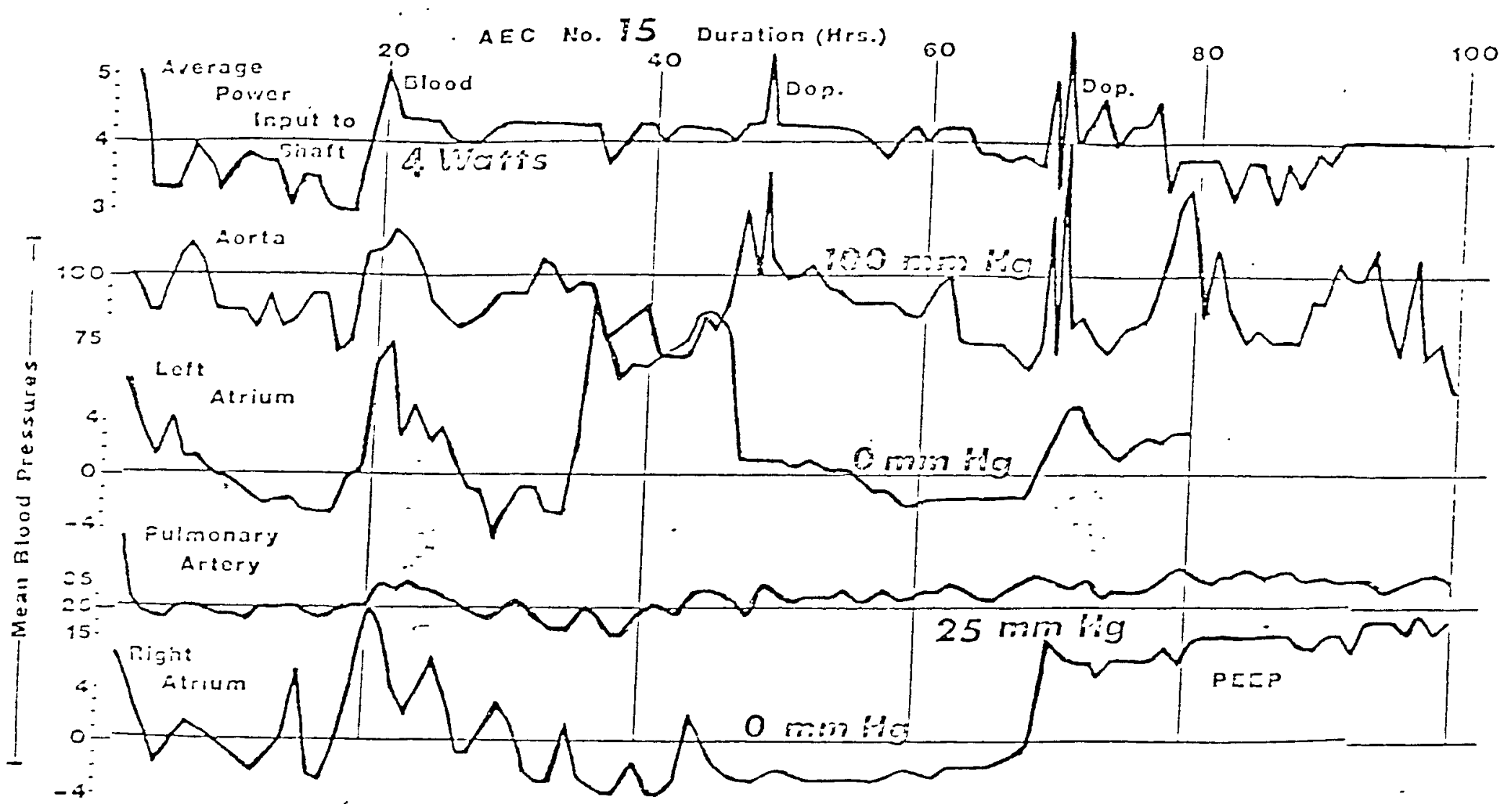

FIgURE 1. Physiological Data From

Experiment $A E C 15$ 
MEC IOIAL ARTHICIAL HLART RIILACIIII II

University of Ulah, Divasion of Artificial Organs

EXPERIMENT HO.: TH74 C41 AEC 15

DATE: November 21,1974

HOURS SURVIVAL: $100+$ NIIIIINL WEIGHIT: $98 \mathrm{~kg}$

PURPOSE: Evaluation of AEC blood pump with $3 / 16^{\prime \prime}$ drive shaft core and reinforced shaft casing.

BLOOD PUIP SYSTEII SATISTACTORY ORLRATLUA (,')

HEART:

Ventricle Composition:

Silastic with fibrils

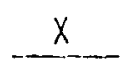

Puinip) No.:

WANL \#2

$x$

Valves:

Bjork-Shiley Carbon

$\underline{x}$

Quick Connects :

Plastic polycarbonate

X

ORIVIIG SYSTEM:

Electric llotor:

Electrocraft $E-550$

$x$

Coolant System: Modified electric fuel pump

$x$
DRIVE COUPLIHG SYSTLII:

Shaft Type:

Stowe \#S-35 8"

$x$

Core/size: Hollow core, $3 / 16^{\prime \prime}$ diameter

Casing Material/Construction Neoprene rubber

Liner:

Bronze

Length:

$8^{\prime \prime}$

PARAMLTLRS MONITORIO).

Physologual. Aorlic, Pulmomery veill, right alrial $x$

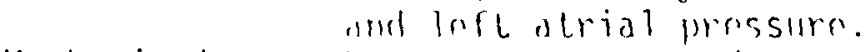

Mechmical: Vacumin, motor speed, torque at temperature.

CAUSE of IOAAII: lerminated because of severe bronchial pneumonia.

NIIIAL NCTIVITY. Minimal activity after second suryery. Animal stood $4-5$ minutes at 6 hours into experiment. 


\section{PREPARATIONS FOR RECEIPT AND USEAGE OF THERMAL CONVENTOR}

\section{AND PLUTONIUM SOURCES}

Preparations are being made for facilities to receive, store, monitor and utilize the thermal convertor and plutonium power sources when they arrive at the Institute of Biomedical Engineering. As detailed in the Institute's Application for Amendment No. 6 to our Special Nuclear Materials License (SNM-663 which was approved and granted in August 1974) to the AEC Division of Material Licensing (DML), a secure, well shielded storage room at our St. Mark's facility for storing plutonium has been identified, refurbished and is now being equipped and instrumented. The storage room will be equipped with three separate locked doors before entry can be made and a monitor system which will alarm in the event of an attempt at unauthorized or forced entry, high radiation levels or fire in the storage room. See Figure 2 taken from the Application to DML. Detailed, written procedures have been made for routine and emergency handling and accommodation of the plutonium sources, and personnel are being instructed in their implementation. See "Thermal Startup and Shutdown Procedure" and "Surgical Protocol for Thermal Convertor Implantation." See also "Emergency Procedures for Plutonium Sources."

Personnel radiation dosimetry supplies such as self-reading pocket dosimeters have been obtained and TLD dosimetry service will be provided by the University Radiological Health Department. The Institute will be prepared to receive and utilize the thermal convertor and its plutonium power source when it is available. 


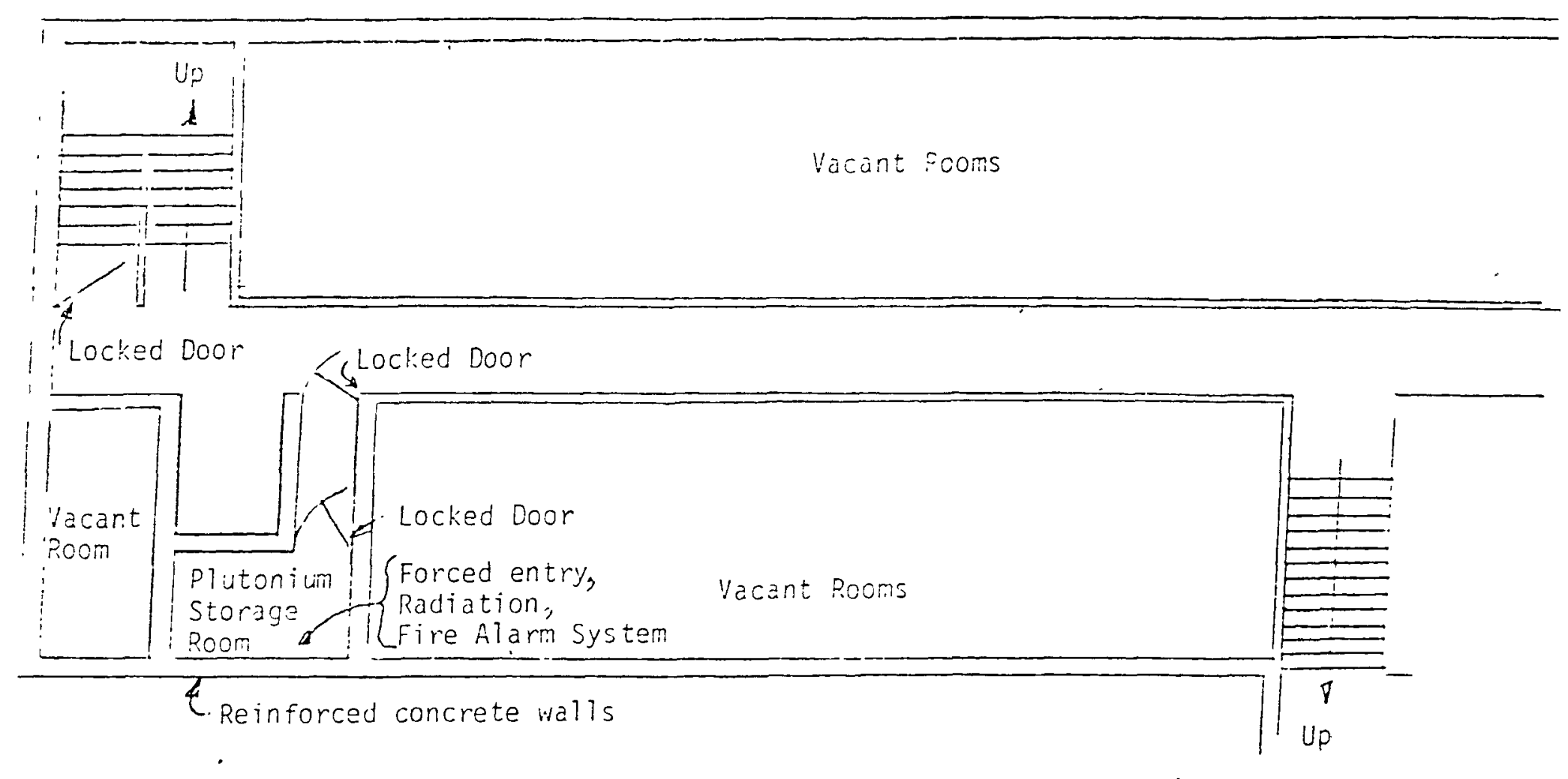

FIXUR: 2

Basement Flonr flan - 2,200 ft ${ }^{2}$
old St. Hart!'s fosoital 


\section{Thermal Converter Startup and Shutdown Procedure}

\section{$\underline{\text { Pu-238 Heat Source }}$}

\section{Startup}

1. Assemble equipment. Thermal converter should be assembled but without Pu-238 heat source installed.

2. Mount thermal converter and thermal converter cooling water connections, auxiliary oil system, argon supply, and instrumentation.

3. Purge thermal converter leaving argon supply attached.

4. Remove Pu-238 heat source from shortage. Place in glove box.

5. Purge glove box. After purge, maintain slight $\left(2^{\prime \prime} \mathrm{H}_{2} 0\right)$ argon pressure inside.

6. Remove hot finger assembly from thermal converter.

7. Insert $\mathrm{Pu}-238$ heat source in hot finger assembly. Start thermal converter cooling water.

8. Install fueled hot finger assembly on thermal converter.

9. Start auxiliary oil system and pressurize thermal converter with argon using the following procedure. Start auxiliary oil pump and gradually increase the argon gas pressure per established procedures until equilibrium is reached at 200 psig. The oil pressure should then read 135 psig. The difference between average gas pressure and oil pressure should be 50 to 65 psig through this process.

10. Connect flex shafts. Use starter motor or hand crank to turn over engine. After engine starts, control speed by starter motor or dynamometer. If starter is used, remove starter motor and place cap over shaft end. 
11. Control speed by dynamometer until thermal converter conditions stabilize. When stable, adjust engine speed control to hold speed under varying load.

12. Isolate or disconnect thermal converter from auxiliary oil system. 


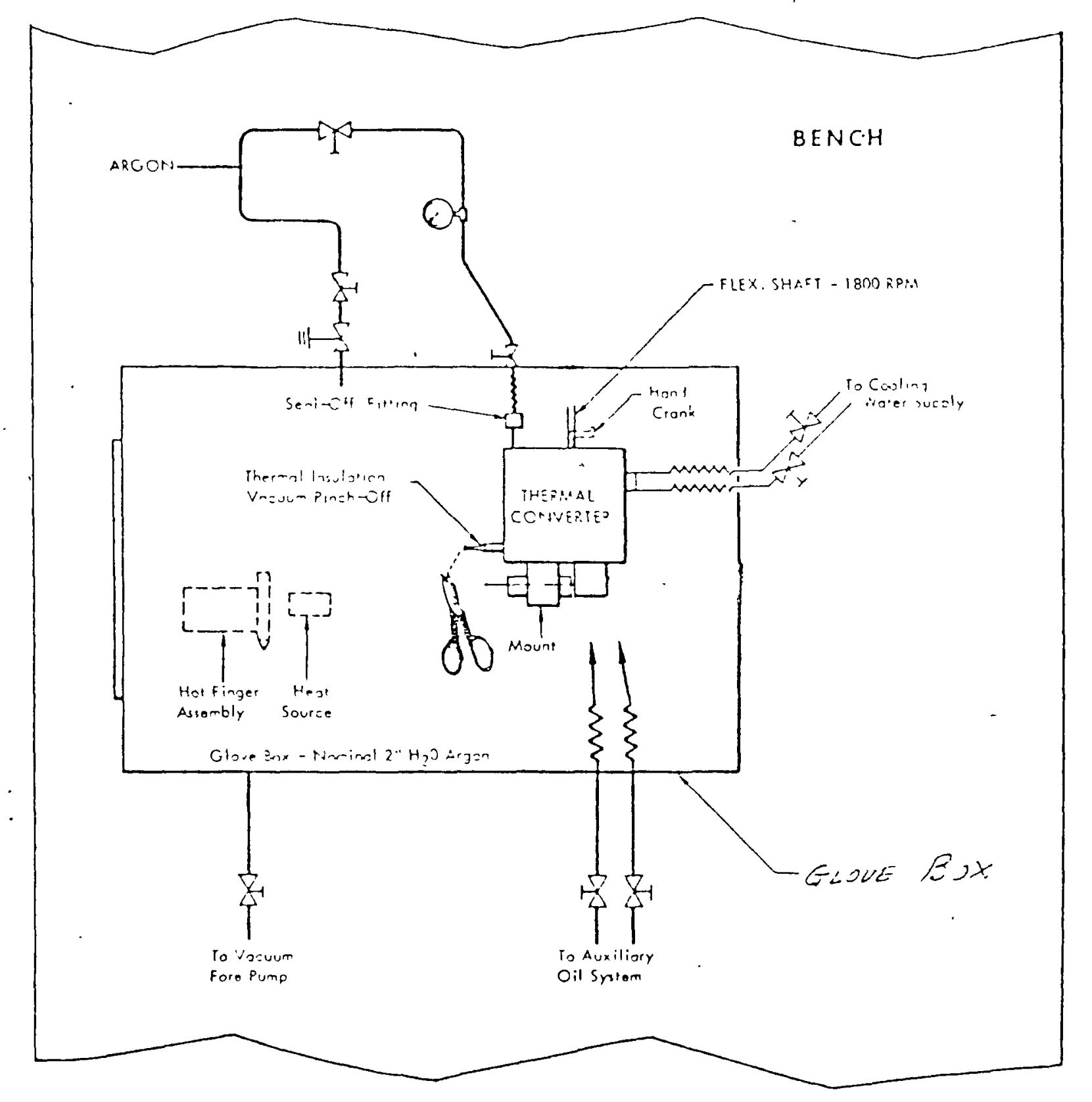

Figure. System Start-up Schemotic 


\section{Shutdown}

1. Activate or connect and activate auxiliary oil system.

2. Block engine speed control in full throttle position.

3. Overspeed engine by $10 \%$ by reducing dynamometer load. Allow heat source to cool approximately $100^{\circ} \mathrm{C}$.

4. Stall engine and depressurize (quickly).

5. Remove hot finger assembly from thermal converter.

6. Remove Pu-238 heat source from hot finger assembly. Allow to cool.

7. Replace hot finger assembly on thermal converter.

8. Inactivate test setup in same manner as for electrically heated thermal converter.

WARNING: During any of these procedures, the hot finger temperatures should be continuously monitored. If any temperature exceeds $1800^{\circ} \mathrm{F}$, destroy thermal insulation vacuum by cutting the vacuum pinch-off. 


\section{Surgical Protocol for Thermal Converter luylantalion}

\section{Criteria for Implantation}

Stable preparation usinc available physiolonical parameters. The animal is eating and drinking with no $0_{2}$ support and standing a minimum of 48 hours.

Procedure.

Pre-0 op

1. Thermal converter has been sterilized and is running on auxiliary cooling.

2. Anesthetize and intubate and surgically prep the animal.

3. Incise through former abdominal incision and expose the near box and electric untor.

4. Prepare site for themal converter using dummy for space requirements.

5. Heparinize.

6. Remove runnina thermal converter with auxiliary cooler lines from its sterile chamber.

7. Place thermal converter in proximity to gear box.

8. Remove nut cover from gear box.

9. Stop thermal converter (10 minutes maximun). (Can be restarted with external power source.) Coolants are circulating.

10. Stop electric motor; start timer at 60 seconds, restart electric motor.

11. Effect the matiny, including sperm oil charge.

12. Restart electric notor.

13. Connect cooling system.

14. Monitor blood pressures and temperatures. 
15. Pemove elechic lixtor and cap motor conneclor.

16. Hith oil filted syringe, enquese blecding bort on gear hox and charge with sperm oil and remove and create air creating mild vacuun. Cap self sealing bleeding port. 


\section{Accidents}

The only internal failure of real concern would be an inadvertent stall of the thermal converter after operating conditions are reached. Under these conditions it is expected that the temperature of the capsule could reach temperatures as high as $2350^{\circ} \mathrm{F}$ in as little as one hour if the vacuum in the insulation space were maintained . and the capsule were not removed from the hot finger. The three thermocouples that measure the hot finger temperature in the heat source location will be continuously monitored either by personnel or by an alarm.

In the event that alarm monitoring is being used, thermal insulation will be installed with auxiliaries that will break the insulation vacuum seal and backflood the insulation with helium and ruin its insulation capability. Based on bench model experience using a similar system, capsule temperatures after backflooding quickly reduce to less than $300^{\circ} \mathrm{F}$.

In the event that the system is being monitored by personnel when an engine stall accident occurred, the procedure would be somewhat different. First an attempt to restart would be made. Second, if restart failed, an attempt to remove the hot finger and then remove the capsule would be made. Third, if the second procedure failed also, the vacuum seal on the thermal insulation would be broken manually and the insulation allowed to fill with the argon in the glove box in which the nuclear thermal converter or nuclear system tests will be carried out.

In the event that the alarm system failed to function properly or that personnel

did not respond to the accident condition at $2350^{\circ} \mathrm{F}$ the Udimet material of the structural portion of the hot finger would melt. This would flood the insulation with the engine working fluid which is argon. This also would relieve the overtemperature condition. In the event that the engine stall had been caused by a loss of working fluid, the 
pressure in the engine would still be at least as great as the local ambient, or about one atmosphere, and it takes less than 1/10 of an atmosphere gas pressure to totally ruin the insulation's effectiveness. Rather obviously this latter "safety procedure" would destroy the engine and test program. However, the integrity of the radioisotope capsule would not be threatened because of the $2500^{\circ} \mathrm{F}$, two hour fire capability of the capsule.

In view of the building characteristics it is considered incredible that any building fire could generate enough heat to violate the capsule integrity. With respect to external failures, what we have said concerning forces and temperatures for the therman converter is also true for the capsule in storage. 


\section{Emergency Procedures for Plutonium Sources}

General instructions for emergency procedures are given in the University of Utah's Radiological Safety Manual. However, it is deemed desirable that specific instructions and emergency procedures be established relating to the storage and utilization of $\mathrm{Pu}$ sources at Saint Mank's Hospital.

1) Fire

a. Immediately notify Salt Lake City Fire Department by telephone or alarm box. Telephone number: 363-4401. Location of alarm boxes: on each floor near elevator.

b. Evacuate the threatened areas of all personnel except those necessary for imperative duties.

c. Ascertain the specific location and extent of the fire and if possible employ immediately available fire fighting equipment to extinguish the fire.

d. Notify Gary Sandquist at 581-7372 (home: 486-8521), Robert Pendleton, Radiation Safety Officer at 581-6141 (home: 466-2705), Lee Smith at 581-6991 (home: 467-9877), W. J. Kolff at 581-6296 (home: 582-3056) or Don Olsen at 581-6991 (home: 272-0160).

e. Determine the actual location of all $\mathrm{Pu}$ sources by examining the $\mathrm{Pu}$ locater board. If all $\mathrm{Pu}$ Sources are in the storage room, inform the Fire Department of their location upon their arrival. If it appears that an extreme fire threat exists in the Pu source storage area, request that the Fire Department flood the storage room.

$f$. If any $\mathrm{Pu}$ source is not in storage and may be threatened by the fire, it should be removed from the building if possible and placed in custody of Gary Sandquist or Robert Pendleton for safe keeping . 
g. If the Pu source is implanted in an experimental animal, the experiment should be immediately terminated and either the animal removed from the building or the Pu source surgically removed from the animal and then taken from the building .

\section{2) Bomb Threat or Riot}

In the event of a bomb threat or other violent threat directed at Saint Mark's Hospital or its personnel, the following actions should be taken:

a. Immediately notify the Salt Lake City Police Department by telephone at 328-7111. If this is not possible, use a fire alarm box in the building or (unobtrusively if under immediate personal threat) trip outside alarm.

b. Determine (unobtrusively if necessary) the actual location of all Pu sources by examining the $\mathrm{Pu}$ locater board. If possible return $\mathrm{Pu}$ sources to secure storage.

c. Do not indicate the existence or location of the $\mathrm{Pu}$ sources to intruders unless under immediate personal threat.

d. If under immediate personal threat, comply with the demands of the intruders, bur carefully observe each intruder so that an accurate description of each intruder can be supplied later to the police and FBI.

3) Earthquake, Flooding and Other Natural Disasters

Such disasters pose no immediate threat to the $\mathrm{Pu}$ sources and primary emphasis is upon minimizing personnel injury from the natural disaster. Operations for recovery of the $\mathrm{Pu}$ sources will be under the direction of Gary Sandquist and Robert Pendleton. 